\title{
THE DYNAMICS OF RAPE IN MODERN INDIAN SOCIETY
}

\author{
V. K. Madan, R. K. Sinha
}

\section{K. Madan}

Department of Electronics and Communication Engineering Kalasalingam University, Krishnankoil, India

*Correspondence: V.K. Madan, Kalasalingam University, Krishnankoil (TN), 626126, India

E-mail: klvkmadan@gmail.com

\section{R.K. Sinha}

Ex-International Institute for Population Sciences, Govandi Station Road, Mumbai, India *Correspondence: R.K. Sinha, IIPS, Govandi Station Road, Mumbai 400088, India E-mail: rksinha35@gmail.com

\begin{abstract}
Rape is malum in se. In modern India the institution of rape has flourished immensely in recent times, and presently it is a national problem. It is a challenge to the contemporary thinking. Gender equality is enshrined in the Indian constitution. In ancient times rape existed in Europe while women in India had divine personification as Shakti and in modern times millions of Indians visit Shakti temples with liberal offerings.

This paper addresses dynamics of rape with particular reference to India. Rape is a multidimensional and dynamic phenomenon. Its perception may vary from radical to liberal, and the legal definition keeps evolving. Mathematically it may be modeled as a space-time function. In 2013 the definition of rape was revised both in India and US. It, however, differs. The paper examines recently introduced Indian law to reduce rape incidents.

There are various areas which need attention to have insight into the phenomenon of rape and measures to control the incidents. This includes understanding the effect of socioeconomic-demographic predictor variables in reduction of the incidents. The authors have applied statistical analysis using correlation to rape data from all the 35 regions of India with eleven socio-economic-demographic predictor variables to find the effect of the variables on incidents of rape. It was found that only literacy status, or literacy status as a proxy, for male and female in urban population indicated significant desirable effect on the number of rape incidents. This sets a direction for further research. The rape challenge should be addressed with afresh look from multidisciplinary perspective besides law and enforcement. The fusion of data, analyses, and ideas including from sociological, cultural, psychological, and religious aspects, and encouraging merging of tools from disciplines, should provide an insightful and sound approach to find solution to the intractable social problem. Also social change with the universal wisdom thoughts of great minds like Mahatma Gandhi and Elie Wiesel is desirable to eliminate ills, including rape, from the modern society.
\end{abstract}

Keywords: rape, literacy, Indian penal code, space-time function, socio-economicdemographic predictors, multidisciplinary perspective, statistical analysis, correlation, religion.

\section{Introduction}

Rape is grave wrong. It is malum in se and can have severe consequences for victims. It has been occurring since the ancient times across cultures. It has too often been ignored and mischaracterized. Rape is a complex phenomenon with many dimensions. It is one of the most controversial issues, and is a challenge to the contemporary thinking. It is perhaps the 
most under-reported crime. However it is on the increase despite changes in the legislation, practice and procedure in the investigation, high profile coverage in the media, and support available to the victims. However only a small number of perpetrators are brought to justice, and victims are routinely blamed for the crime. Dealing with rape is much more complex than dealing with most other crimes.

In India rape is horrific fact of life, a common occurrence that makes everyday news, and in recent times the incidents have increased sharply. Gruesome crimes against women have become rampant. A high profile savage gang rape case in December 2012 where a student was gang raped with unimaginable acts of cruelty. It pricked the conscience of the nation with unprecedented protests and drew the world attention. Again in August 2013 a similar brutal gang rape case in Mumbai stirred memories similar to the December 2012 case.

Recently the United Nations Secretary General Ban Ki-moon urged the Indian government to take action to protect women, and the United Nations High Commissioner for Human Rights Navi Pillay called rape in India a national problem. The Government of India acted swiftly, modified laws and had set up fast-track courts to deal with the crime. It is ironical that in spite of awakening, the sexual assaults continue to rise while gender equality is enshrined in the constitution. In modern India women occupy position of leadership in almost every field.

The paper describes dynamics of rape in the modern Indian society, and possible reasons for the crime. The history of rape law was traced, and current law with amendment was examined. Quantitative statistical analysis using correlation was employed on rape data with eleven socio-economic-demographic predictor variables. It was found that literacy plays an important role in reduction of the crime. It may be mentioned that to effectively contain rape crime requires a fresh look with multidisciplinary approach to gain insight and find solution to the intractable social problem.

\section{Introduction to the Study of Rape}

The English word rape is derived from Latin word rapere. The Merriam Webster dictionary defines rape as "unlawful sexual activity". However there can be several types of rapes like penetrative, non-penetrative, consensual, marital, and the crime of rape varies culturally.

Rape is not a modern phenomenon. Rape has been described in early religious texts in the western world. Greek mythological god Zeus raped women including Hera, Io, and Phoenician princess Europa, and the continent Europe is an eponym of the Princess. In ancient Rome rape had been reported e.g. the Rape of the Sabine Women. Rape was considered as a less crime for a particular girl than with the other girl like rape of a nonvirgin was less crime than rape of a virgin. About three centuries back in France, marrying without parental consent was considered rape.

In Indian constitution gender equality is enshrined with provision of positive discrimination in favor of women. In modern India women occupy position of leadership in most fields. Even in ancient India women enjoyed status equal to men or even better. The divine personification of feminine power was and is known as Shakti. In India there are many temples dedicated to Shakti like Mata Vaishno Devi Mandir where number of annual pilgrims are over ten million and a nearby expansive modern university by the same name is funded by offerings by pilgrims at the Mandir. It confirms faith in the goddess by a large number of followers even in modern India. However rape as a national problem exists.

The reasons for rape include sexual pleasure, socioeconomic, power, sadism, anger, and evolutionary. For example persons in power can coerce mating with little fear of reprisal.

The perception and understanding of rape varies widely. The two extreme views are liberal and radical, and it is generally perceived somewhere between the two extremes. Liberal perception views rape as an assault like other assaults while the radical perception takes into consideration dominant role because of manhood. The judgment of rape can therefore be subjective. In some societies rape is a taboo for the victim. 
The legal definition may vary depending on the country and time. In mathematical parlance rape may be described as a function of space and time. For example the definition of rape in US has been revised since January 2013 as "Penetration, no matter how slight, of the vagina or anus with any body part or object, or oral penetration by a sex organ of another person, without the consent of the victim". Marital rape was considered a crime in the US and the same has since been abolished. Since February 2013 in India the word rape has been substituted by the word "sexual assault" and it includes assault without penetration and new offences. The lack of physical resistance is immaterial. In contract in Germany the victim has to prove that sufficient resistance was put to avoid the assault for example in 2012 the judgment went against a 15 year old female rape victim. The judge pronounced "Es hătte weglaufen oder Hilfe rufen konnen, aber es hat alles iiber sich ergehen lassen. Das reicht nicht, um jemanden zu bestrafen" implying that not enough resistance was put. However in some societies like in Afghanistan rape is the ultimate taboo for the victim and the law and society imprison the victim. Elie Wiesel's wisdom thought "There may be times when we are powerless to prevent injustice, but there must never be a time when we fail to protest" is apt in this and similar situations.

The impact of rape on victims can be severe. A victim may get severely traumatized, suffer from various stress disorders, and face social stigma. Many victims consider it as a moral injury. Many are harmed in their sexuality for a long time. The victim has to bear humiliation and shame. The victim's family may resort to honor killing or forced marriage to the rapist. To help victims there are institutional support centers, both governmental and NGOs. They have enhanced sensitivity and understanding of rape, and help victims including healing the damage. However there are a significant number of silent victims as rape is one of the most under-reported violent crimes. The reasons may include social stigma, fear of reprisal from the perpetrator, the attitude of the police, painful medical examination, possible humiliation in the court by the defense attorney, and in some societies the victim is imprisoned.

\section{Indian Penal Code and Recent Amendments}

The Indian Penal Code (IPC) describes an exhaustive list of all cases of crime and punishment. The first IPC document was prepared in 1860 with 511 sections, and came into force in 1862. Many amendments have since been made the IPC. However in the state of Jammu and Kashmir the IPC is known as Ranbir Penal Code (RPC). The IPC takes into account actus reus, mens rea, and the fundamental maxim "actus non facit reum, nisi mens sit rea" meaning the act is not culpable unless the mind is guilty. For example mens rea translates in the IPC as intentionally, knowingly, voluntarily, fraudulently, or dishonestly.

There are two sections in IPC pertaining to rape viz. section 375 and section 376. In 375 IPC a man is said to commit "rape" to a woman in a circumstance like against her will, without her consent under false promise, consent by coercion, with her consent when she has unsound mind or intoxication and is unable to understand the nature and consequences of that to which she gives consent, or with or without her consent when she was under 16 years of age. The section 376 defines a minimum punishment of seven years for the perpetrator. The punishment covers an exhaustive list of rape situations like punishment for a public servant, police, and gang rapists.

After the December 2012 Delhi gang rape case, the Government of India constituted a judicial committee headed by Justice J.S. Verma to suggest amendments in criminal laws and punishment to deal firmly in sexual assault cases, and based on the recommendations of the committee a Criminal Law (Amendment) Act 2013 was passed. The word rape has been replaced with sexual assault and it includes assault without penetration, and penetration to any extent other than penile penetration is also an offence. New offences have been added like acid attack, sexual harassment, voyeurism, stalking with related punishments.

\section{Indian Rape Statistics and Analysis}

There are various areas which need attention to gain insight into the phenomenon of rape and measures to control the incidents. This includes understanding the effect of socioeconomic-demographic predictor variables in reduction of the incidents. In this study statistical analysis using correlation was employed for the analysis of 2012 rape data from 
all India consisting of 35 regions representing 28 states and seven union territories. Eleven predictor variables were used to find the effect of the variables on incidents of rape. The predictors selected were male and female literacy in rural, urban, and total population, sex ratio, percentage of rural and urban population, work participation rates for male and female population. The rape data taken were from the National Crime Records Bureau under Section 376 IPC, and predictor variables chosen were from the 2011 Census Data. Predictors were taken as the independent variables while rape rates defined per lakh $(1,00,000)$ of population were taken as the dependent variables. It may be mentioned that in India Vedic numbering system is used to denote large numbers like lakh (also lac), crore $\left(\mathrm{IO}^{7}\right)$, arab $\left(10^{9}\right)$, and kharab $\left(10^{11}\right)$.

Table 1 depicts descriptive statistics of rape rate and the variables for all the 35 regions of India. It is observed from the Table that the mean value of rape rate was 2.8 with standard deviation of 2.04 across the regions. Mean value of male literacy ranged from 91 to 82 for urban and rural areas respectively, and for the total region it was 85 with relatively lower standard deviation values across the regions. Mean values for female literacy ranged from 82 to 66 for urban and rural areas, and for total combined areas it was 71. Mean Sex ratio was 929 and that is number of females per thousand of male population. Mean values for rural and urban percentages to total population were 61 and 39 respectively with the same standard deviation of 22 across the regions. Mean values for male and female work participation rates were 54 and 26 respectively with relatively lower standard deviation across the regions.

Fig. 1 depicts 2012 rape rates across 28 states and seven union territories of all India. Mizoram state had the highest rape rate of 10.1 per lakh of population while the union territory of Lakshdeep had no reported rape incident. The reasons of highest rape rate in Mizoram include both high incidence of the rapes and high incidence of reporting. In Mizoram the overwhelming population is Christian and Christian ethics of forgiveness is misused and there is little fear of reprisal for committing crime coupled with and grim drug abuse problem there. In Lakshdeep women enjoy a respectful status. More than $40 \%$ of households are headed by women unlike in the rest of India.

Further bivariate correlations were computed between the predictor variables and rape rates across the Indian regions. All variables considered were on interval scale. 
Table 1: Descriptive Statistics

\begin{tabular}{|l|l|l|l|}
\hline & Mean & Std. Deviation & $\mathrm{N}$ \\
\hline Rape Rate & 2.7886 & 2.04346 & 35 \\
\% Male Lit. (T) & 85.2717 & 6.32653 & 35 \\
\% Male Lit. (R) & 82.3357 & 7.05876 & 35 \\
\% Fem. Lit. (T) & 71.4677 & 10.48830 & 35 \\
\% Fem. Lit. (R) & 66.0589 & 11.31427 & 35 \\
\% Fem. Lit. (U) & 82.1720 & 6.23847 & 35 \\
Sex Ratio & 929.30 & 79.682 & 35 \\
\% Rural & 61.2140 & 22.20706 & 35 \\
\% Urban & 38.7860 & 22.20706 & 35 \\
WPR(M) & 54.4029 & 5.11897 & 35 \\
\hline WPR (F) & 26.3114 & 9.68427 & 35 \\
\hline
\end{tabular}

Fig. 1. Rape Rate across Indian States and Union Territories in 2012

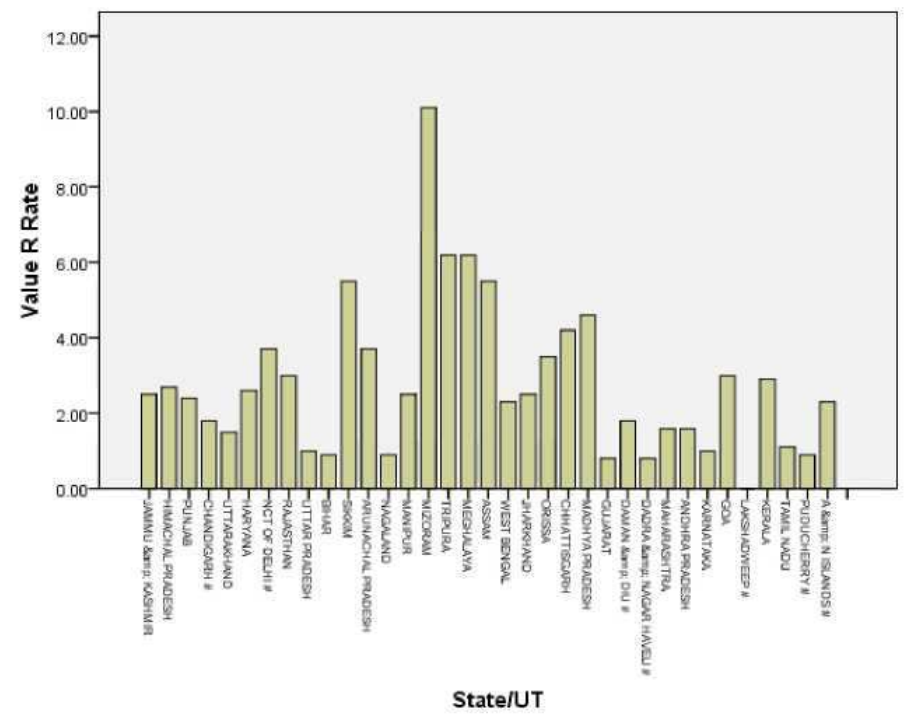


Table 2 depicts correlation coefficients of rape rates with predictor variables. It is observed that out of the eleven predictors, only male and female literacy status in urban population had significant effect on reduction of rape incidents. The strength of association was relatively significant at 5 percent significance level with 2-tailed sigma or $\mathrm{p}$ values of 0.032 and 0.014 . Literacy is definitely a key indicator to reduce the crime. The correlation analysis, however, does not take into account of independent effects of the predictors on the dependent variable. It provides indication for further research using advanced techniques to explore more closely for the independent effect of the predictors on the rape rate. Literacy can, however, be a proxy for development related factors.

Table 2: Correlation Coefficients

\begin{tabular}{|l|l|l|l|}
\hline \multirow{2}{*}{ Variables } & \multicolumn{2}{|l|}{ Rape Rate } \\
\cline { 2 - 4 } & Coefficient & Sig. (2-tailed) & N \\
\hline Rape Rate & 1 & .000 & 35 \\
\% Male Lit. (T) & .022 & .899 & 35 \\
\%Male Lit. (R) & .014 & .938 & 35 \\
\% Male Lit. (U) & $-.363^{*}$ & .032 & 35 \\
\% Fem. Lit. (T) & .177 & .308 & 35 \\
\% Fem. Lit. (R) & .178 & .307 & 35 \\
\% Fem. Lit. (U) & $-.412^{*}$ & .014 & 35 \\
Sex Ratio & .175 & .316 & 35 \\
\% Rural & .197 & .256 & 35 \\
\% Urban & -.197 & .256 & 35 \\
WPR(M) & -.080 & .650 & 35 \\
WPR (F) & .287 & .094 & 35 \\
\hline
\end{tabular}

*. Correlation is significant at the 0.05 level (2-tailed).

\section{Conclusions}

Rape is malum in se. In India it has increased sharply in recent times and presently it is a national problem. It has drawn world attention including from UNO. Recently the Government of India modified laws and had set up fast-track courts to deal with the crime.

Rape is a challenge to the contemporary thinking. It is perhaps the most under-reported crime. Dealing with rape is much more complex than dealing with most other crimes. It is irony that rape cases in India are on the increase while gender equality is enshrined in the constitution, and in modern India women occupy position of leadership in almost every field. Many Indians, as in ancient times, still consider divine personification of women and visit Shakti temples with liberal offerings.

The paper addresses dynamics of rape and models it as a space-time function. Rape is a multidimensional and dynamic phenomenon. The perception and understanding of rape may vary widely. The two extreme views of rape are liberal and radical and the rape is generally perceived in between these extreme views. The judgment of rape may therefore be 
subjective. The definition of rape keeps evolving and is country specific. In some societies rape is the ultimate taboo for the victim.

The authors have applied statistical analysis using correlation on the Indian rape data punishable under Section 376 IPC with eleven socio-economic-demographic predictor variables. The data taken were for all the 35 regions representing all India. The result of the analysis indicated that out of all the predictor variables chosen, only male and female literacy status in urban population or literacy status as a proxy indicated significant effect on reduction of rape incidents. The future work may include application of advanced statistical techniques to the analysis of the rape data to get deeper insight into the problem. It may be suggested that more predictor valuables be used for the analysis to unfold their effect on rape incidents.

It may be stressed that laws are necessary but not sufficient to contain rape incidents. It is desirable that the rape challenge should be addressed with a fresh look from multidisciplinary perspective besides law and enforcement. The fusion of data, analyses, and ideas including from sociological, cultural, psychological, and religious aspects, and encouraging merging of tools from disciplines, should provide an insightful and sound approach to find solution to the intractable social problem.

The social change with the universal wisdom thoughts of great minds like Mahatma Gandhi and Elie Wiesel is desirable to eliminate ills, including rape, from the modern society. Mahatma Gandhi's thought on religion "... our innermost prayer should be a Hindu should be a better Hindu, a Muslim a better Muslim, a Christian a better Christian" puts the religions in the right perspective in building character, and Elie Wiesel's thought "There may be times when we are powerless to prevent injustice, but there must never be a time when we fail to protest" helps in gaining inner strength with desirable action even in extreme conditions. High character and moral strength would make the society courageous and free from ills including rape.

\section{Bibliography}

http://www.indiatimes.com/news/india/burn-them-alive-delhi-gangrape-victims-lastwords-100477.html;

http://www.hindustantimes.com/India-news/Mumbai/Mumbai-gang-rape-victimidentifies-minor-accused/Article 1-1117462.aspx;

http://www.fbi. gov/about-us/cj is/ucr/recent-program-updates/reporting-rape-in^ $\mathrm{O} 13$; http://mha.nic.in/pdfs/criminalLawAmndmt-040213.pdf;

https://www.maavaishnodevi.org/;

Zalta, Edward N. (editor), The Stanford Encyclopedia of Philosophy, 2012. URL = http: I/pi ato. Stanford. edu/.

Office of the Registrar General \& Census Commissioner of India, 2011 Census Data, New Delhi, 2012;

Crime in India, National Crime Records Bureau, Government of India, 2012 Statistics, New Delhi 2012;

Gupta, S.C., Fundamentals of Mathematical Statistic?,, Sultan Chand \& Sons, eleventh edition, New Delhi, 2002;

Ministry of Home Affairs, Government of India, Indian Penal Code, New Delhi, 2013;

http://www.hertener-allgemeine.de/lokales/marl/Maedchen-hat-sich-nicht-genuggewehrt;art996.833782; 